\title{
Cellulose sulfuric acid (CSA) and starch sulfuric acid (SSA) as solid and heterogeneous catalysts in green organic synthesis: recent advances
}

\author{
Rajesh H. Vekariya and Hitesh D. Patel* \\ Department of Chemistry, School of Sciences, Gujarat University, Ahmedabad 380009, Gujarat, \\ India \\ E-mail: drhiteshpatel1@gmail.com
}

DOI: $\underline{\text { http://dx.doi.org/10.3998/ark.5550190.p008.975 }}$

\begin{abstract}
The use of heterogeneous solid acid catalysts is important to the development of sustainable chemical processes. To this end, cellulose sulfuric acid (CSA) and starch sulfuric acid (SSA) have been developed and used for a wide range of organic transformations, including the synthesis of pharmaceutically important heterocyclic compounds. These heterogeneous catalysts are easily recovered and reused several times without loss of their activity. In this review, we mainly summarize applications of these catalysts in synthetic organic chemistry.
\end{abstract}

Keywords: Cellulose sulfuric acid (CSA), starch sulfuric acid (SSA), heterogeneous catalysts, solid acid catalysts, organic synthesis, selectivity, green synthesis

\section{Table of Contents}

1. Introduction

2. Cellulose Sulfuric Acid (CSA)

2.1. Various organic transformations catalyzed by CSA

3. Starch Sulfuric Acid (SSA)

3.1. Various organic transformations catalyzed by SSA

4. Conclusions

5. Acknowledgements

6. References

\section{Introduction}

Synthetic organic chemistry generally involves the use of various solvents and catalysts, which may be toxic, hazardous, corrosive and inflammable. These chemical processes highly influence 
of the environment. Recently, it has become a major issue at a global level. In view of the seriousness of the chemical pollution, the uses of a wide range of these chemicals are being reexamined, leading to a search for the design and development of environmentally friendly and sustainable organic transformations for synthesis of various chemical compounds.

One of the ultimate goals for organic reactions is to reduce the use of harmful organic solvents and use of heterogeneous catalysts instead of homogeneous catalysts, because of the environment and economic regulations. ${ }^{1-4}$ Homogeneous catalysts such as $\mathrm{H}_{2} \mathrm{SO}_{4}, \mathrm{HCl}, \mathrm{HBr}, \mathrm{HF}$, $\mathrm{CH}_{3} \mathrm{COOH}$ and $\mathrm{CF}_{3} \mathrm{COOH}$ are frequently used in organic synthesis. ${ }^{5,6}$ However, these acid catalysts are toxic, corrosive, harmful and difficult to handle. Furthermore, their disposal is a headache for the chemical industry. ${ }^{7}$ In addition, under homogeneous conditions the catalysts are difficult to recover and reuse. ${ }^{8}$ Not only the ecological profile, but also the economic profile is improved, if recyclable heterogeneous catalysts and solvent free conditions can be used. For this reason, over the last few years, enormous advances have been made to achieve environmentally friendly chemical transformations using heterogeneous solid acid catalysts. ${ }^{9-17}$ Heterogeneous solid acids have advantages over conventional homogeneous acid catalysts such as simplicity in handling, decreased reactor and plant corrosion problems, and they can be easily recovered and reused several times without loss of their efficiency.

In recent years, the direction of science and technology has been shifting more towards eco-friendly, natural product resources and reusable catalysts. In this regard, biopolymers are attractive candidates to explore for supported catalysis. ${ }^{18}$ Several interesting biopolymers have been utilized as a support for catalytic applications, such as alginate, ${ }^{19}$ gelatin, ${ }^{20} \operatorname{starch}^{21}$ and chistosan $^{22}$ derivatives.

Cellulose and starch are the most abundant natural polymers and have been widely studied during the past several decades because they are biodegradable materials and a renewable resource. ${ }^{23}$ Its unique properties make it an attractive alternative to conventional organic or inorganic supports in catalytic applications. Therefore, many efforts have been made by researchers constantly to introduce novel heterogeneous catalyzed organic transformation by using cellulose sulfuric acid (CSA) and starch sulfuric acid (SSA), which are more efficient, economical and compatible with the environment. Also, these catalysts can be recovered and reused several times without a decrease in activity. The present article is intended to review briefly recent research progress concerning the synthesis of different organic compounds catalyzed by CSA and SSA.

\section{Cellulose Sulfuric Acid (CSA)}

CSA was prepared according the following procedure: Take $5.00 \mathrm{~g}$ of cellulose in $20 \mathrm{ml}$ of $n$ hexane. The mixture is magnetically stirred and $1.00 \mathrm{~g}$ of chlorosulfonic acid $(9 \mathrm{mmol})$ added dropwise at $0{ }^{\circ} \mathrm{C}$ over $2 \mathrm{~h}$. $\mathrm{HCl}$ gas is immediately evolved. After the addition is complete the mixture is stirred for $2 \mathrm{~h}$ at room temperature. Then the mixture is filtered and the collected solid washed with $30 \mathrm{ml}$ of acetonitrile and dried at room temperature to afford $5.25 \mathrm{~g}$ of cellulose 
sulfuric acid as a white powder. ${ }^{33} \mathrm{CSA}$ is non-explosive, non-hygroscopic and stable at room temperature.

Organic transformations using CSA have many advantages such as a simple work-up process, inexpensive catalyst, environmental friendly, excellent yield of the products with high purity, shorter reaction times and solvent-free reaction conditions. The CSA is solid, heterogeneous catalyst and after completion of organic transformation, it can be recovered and reused several times without loss of its efficiency.

\subsection{Various organic transformations catalyzed by CSA}

Shaabani et al. ${ }^{24}$ have developed an efficient and environmentally friendly method for synthesis of $\alpha$-aminonitrile derivatives through the condensation reaction of amines, aldehydes and trimethylsilylcyanide (TMSCN) by employing catalytic amount of cellulose sulfuric acid (CSA) as a bio-supported catalyst at ambient temperature, which afforded excellent yield of the products (Scheme 1). In order to optimize the reaction conditions, the authors have carried out this reaction with various solvents, such as water, methanol, ethanol, acetonitrile (MeCN), dichloromethane (DCM) and toluene. However, MeCN showed the best results in terms of the yield of the products. Solvent free condition were also used for this reaction, but this did not give the best results. Both aromatic and aliphatic aldehydes afforded excellent yields of the products. In addition, acid sensitive aldehydes such as furfuraldehyde gave the aminocyano compound in high yield. Short reaction times, the recyclability of the catalyst without loss of activity, simple work-up process and use of non-hazardous, non-corrosive and inexpensive solid acid catalyst are superior features of the protocol.

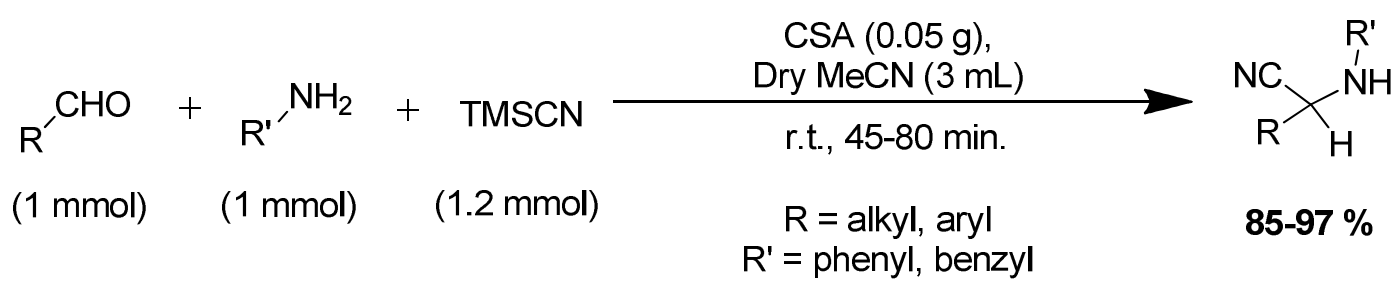

Scheme 1. Synthesis of $\alpha$-amino nitrile derivatives catalyzed by CSA.

An efficient methodology for the synthesis of 4-aryl-1,4-dihydropyridines in excellent yield under solvent-free condition through the three components condensation of various aldehydes, ethyl acetoacetate and ammonium acetate $\left(\mathrm{NH}_{4} \mathrm{OAc}\right)$ at $100{ }^{\circ} \mathrm{C}$, have been established by Murthy et al. $^{25}$ (Scheme 2). The authors have employed this reaction with various solvents such as methanol, ethanol, acetonitrile, toluene, dioxane and tetrahydrofuran (THF). However, these solvents were not efficient for this reaction as compared to solvent-free conditions in terms of the yield of the products. 


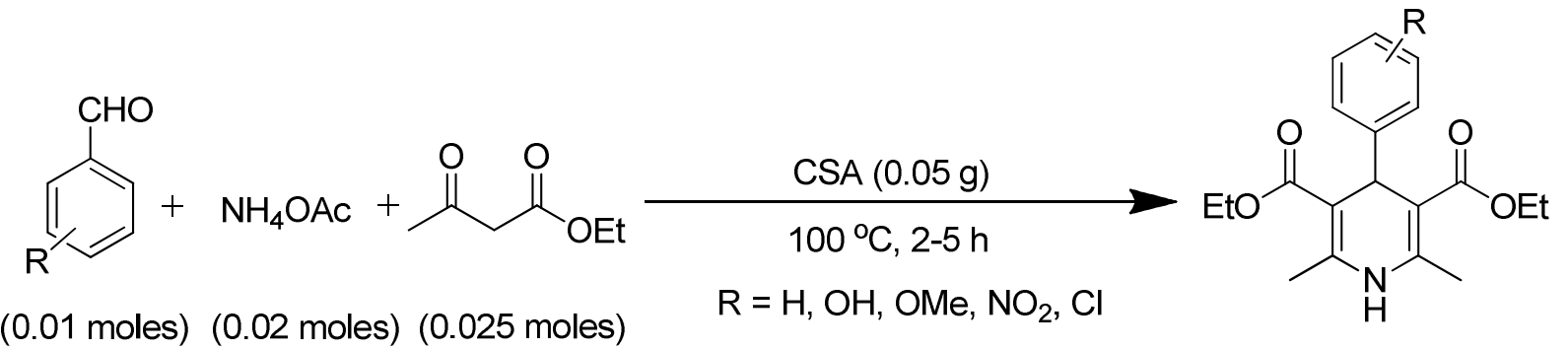

(0.01 moles) (0.02 moles) (0.025 moles)

78-92 \%

Scheme 2. Synthesis of 4-aryl-1,4-dihydropyridines derivatives catalyzed by CSA.

Alinezhad and co-workers ${ }^{26}$ have discovered the solvent-free synthesis of bisindolylmethanes, bis-2-methylindolylmethanes, bis-1-methylindolylmethanes and 3,3'diindolyloxindole derivatives through the reaction of indoles with various aldehydes and ketones in the presence of a catalytic amount of cellulose sulfuric acid, which afforded excellent yields of the products (Scheme 3). This method is also highly chemoselective for aldehydes in the presence of ketones. For comparative study various catalysts such as $\mathrm{ZrOCl}_{2} .8 \mathrm{H}_{2} \mathrm{O}, \mathrm{AlPW}_{12} \mathrm{O}_{40}$, Amorphous zirconium titanium phosphate (15-ZTPA), $\mathrm{NH}_{4} \mathrm{Cl}$, Zirconium tetrakis(dodecyl sulfate) $\left[\mathrm{Zr}(\mathrm{DS})_{4}\right], \mathrm{ZrCl}_{4}$ and CSA were employed in this protocol. However, CSA was proven the best catalyst for this transformation. Also, the reaction was preferably undertaken at ambient temperature rather than high temperature. In addition, solvent-free condition showed better results as comparable to the reaction in solvent like acetonitrile and water. Here, the variety of aliphatic, aromatic and heterocyclic aldehydes and ketones underwent smoothly to the corresponding bis-indolylmethanes in high in excellent yields.

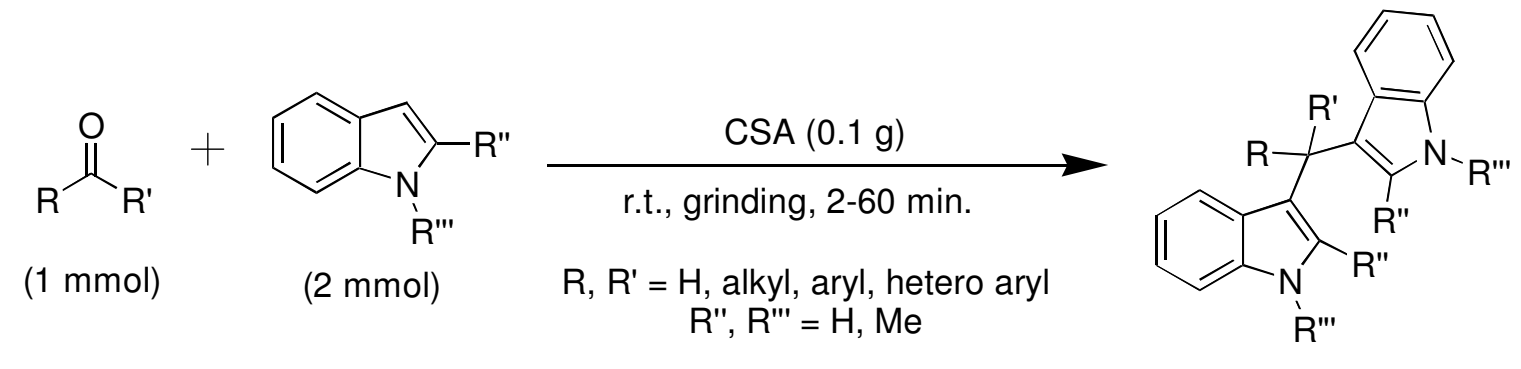

$73-98 \%$

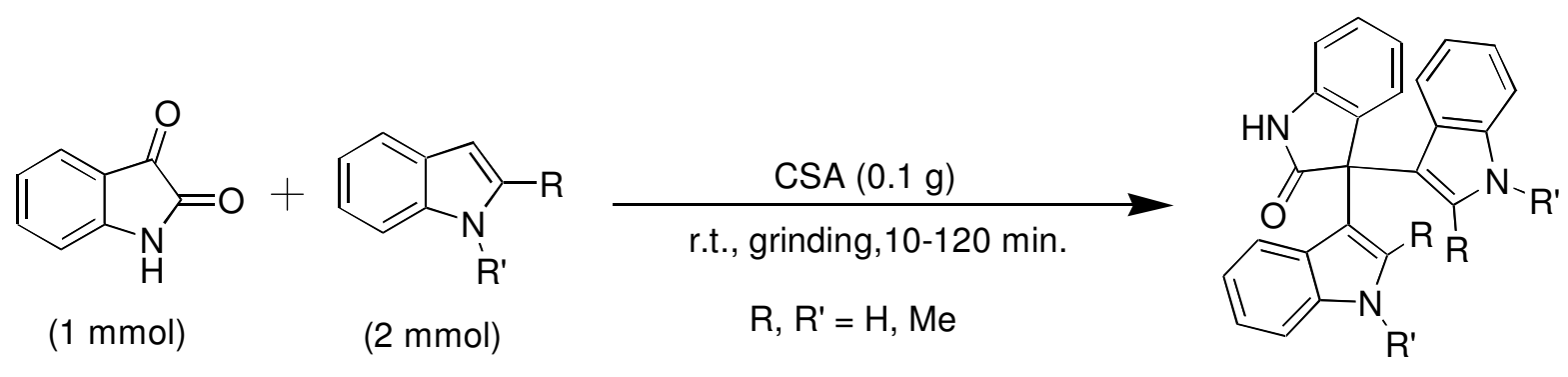

$85-88 \%$

Scheme 3. Synthesis of bis-indolylmethane derivatives catalyzed by CSA. 
A mild, simple and efficient protocol for the diazotization and iodination of various aromatic amines has been developed by Nemati et $a l .^{27}$ employing sodium nitrite and potassium iodide in the presence of cellulose sulfuric acid under solvent-free conditions at room temperature (Scheme 4). In addition, both electron-withdrawing groups and electron-donating groups containing aryl amines were smoothly converted into the corresponding aryl iodides in excellent yields. In comparison with conventional diazotization procedures, acidic effluent is not produced with this protocol, which makes it more "green" and environmentally friendly. In conventional synthesis, ${ }^{28}$ the reaction is usually carried out with sodium nitrite at low temperature in two steps: diazotization of the aryl amine in hydrochloric or sulfuric acid and then reaction with iodine or KI sometimes in the presence of copper salts. The CSA protocol has advantages over the classical process in the use of mild reaction conditions, avoidance of corrosive acids and toxic solvents, and short reaction times.

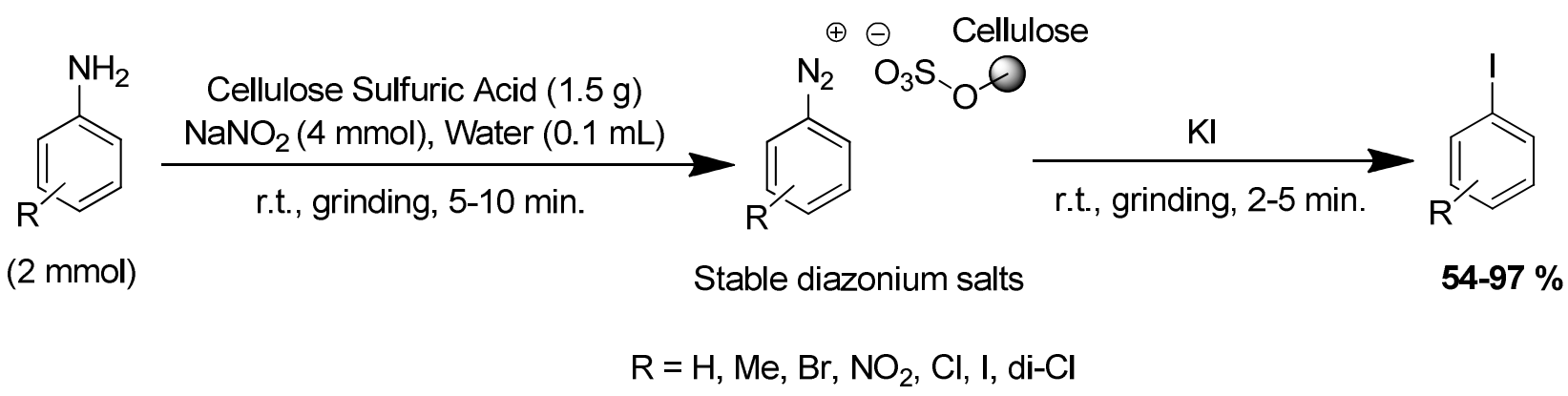

Scheme 4. Diazotization and iodination catalyzed by CSA.

A simple procedure for the synthesis of 6-chloro-8-substituted- $9 H$-purine derivatives involving the one-pot condensation of 6-chloropyrimidine-4,5-diamine and various aldehydes in the presence of catalytic cellulose sulfuric acid (CSA) under solvent-free conditions at room temperature has been disclosed by Maddila and co-authors ${ }^{29}$ (Scheme 5). The reaction did not proceed in the absence of CSA. Lesser amounts of catalyst produced a lower yield of the products, $0.045 \mathrm{~g}$ of CSA gave the best yield.

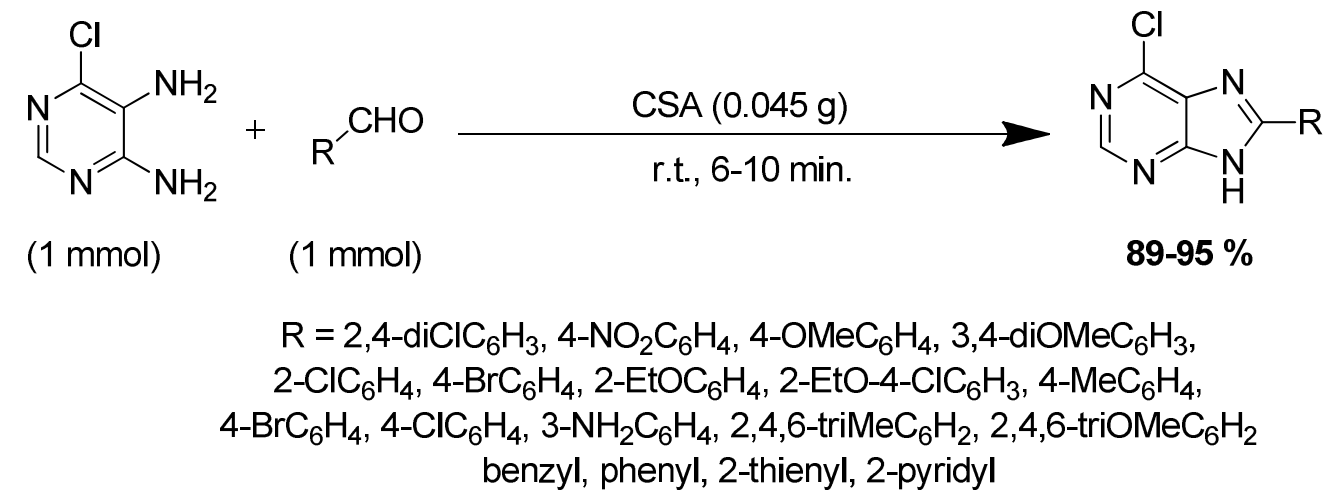

Scheme 5. Synthesis of 6-chloro-8-substituted-9H-purine derivatives catalyzed by CSA. 
An efficient protocol for the synthesis of aryl-14H-dibenzo[a.j]xanthene derivatives from the $\beta$-naphthol and corresponding aromatic aldehydes was developed by Madhav and co-workers, ${ }^{30}$ in the presence of catalytic amount of cellulose sulfuric acid (CSA) under solvent-free condition at $100{ }^{\circ} \mathrm{C}$ to afford excellent yield of the products (Scheme 6). There was no significant change in the yield of the products, when the reaction was carried out at $120^{\circ} \mathrm{C}$ instead of $110{ }^{\circ} \mathrm{C}$, but at $100{ }^{\circ} \mathrm{C}$ the yield of the products becomes lower. Various catalysts such as $p$-toluenesulfonic acid ( $p$-TSA), sulfuric acid in acetic acid and silica sulfuric acid (SSA) were employed in this reaction for comparative study, but they were not efficient as compared to CSA. By this protocol 4-oxo$4 H$-chromene-3-carbaldehyde and 6-nitro-4-oxo-4H-chromene-3-carbaldehyde could be efficiently converted into corresponding aryl-14H-dibenzo[a.j]xanthene derivatives. A significant improvement in the rate of the reaction and the yields of the products was observed, when the reactions were carried out using CSA as compared with the classical acidic catalysts such as acetic acid-sulfuric acid $^{31}$ and $p$-toluenesulfonic acid (p-TSA) ${ }^{32}$. In addition, after completion of the reaction, the CSA could be recovered and reused several times while the conventional catalysts could not be recovered.

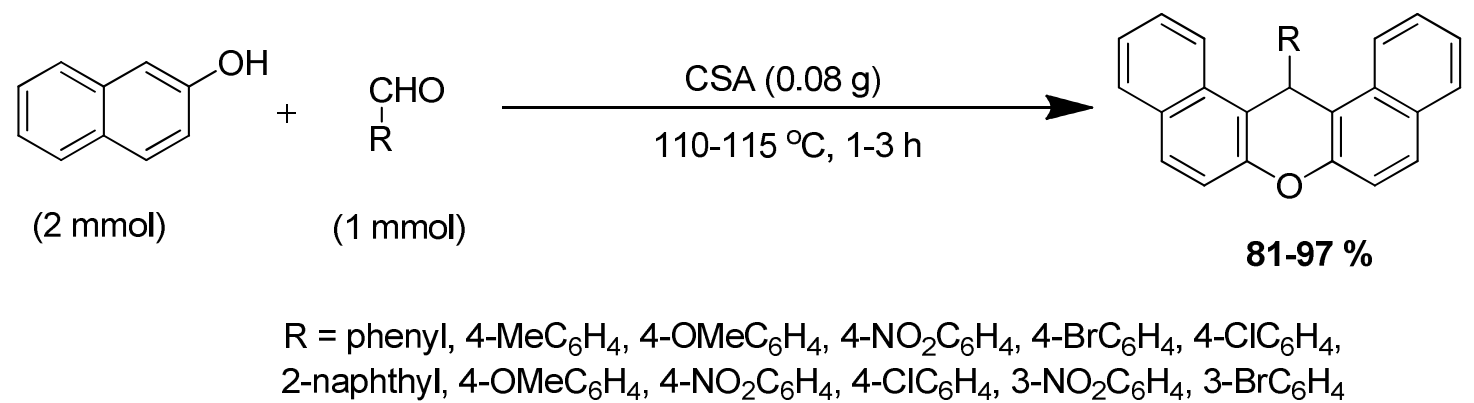

Scheme 6. Synthesis of aryl-14H-dibenzo[a.j]xanthene derivatives catalyzed by CSA.

Safari et $\mathrm{al}^{33}$ have established an eco-friendly method for the synthesis of 1,4dihydropyridines in excellent yields via the one-pot condensation of 1,3-diphenyl-2-propen-1one derivatives, ethyl acetoacetate and ammonium acetate utilizing catalytic amount of cellulose sulfuric acid (CSA) in water under reflux condition (Scheme 7). Only $0.02 \mathrm{~g}$ of CSA was enough for this transformation. To optimize the reaction condition authors have carried out this reaction with different amount of CSA and they have noted that when the amount of CSA was increased from 0.02 to 0.05 , the yield of the products was significantly increased with the reduction in the reaction time. For comparative study authors have carried out this reaction with various solvents such as ethanol, methanol, isopropanol, tertiary-butanol, tetrahydrofuran (THF) and acetonitrile $(\mathrm{ACN})$, but they are not efficient as in water. 


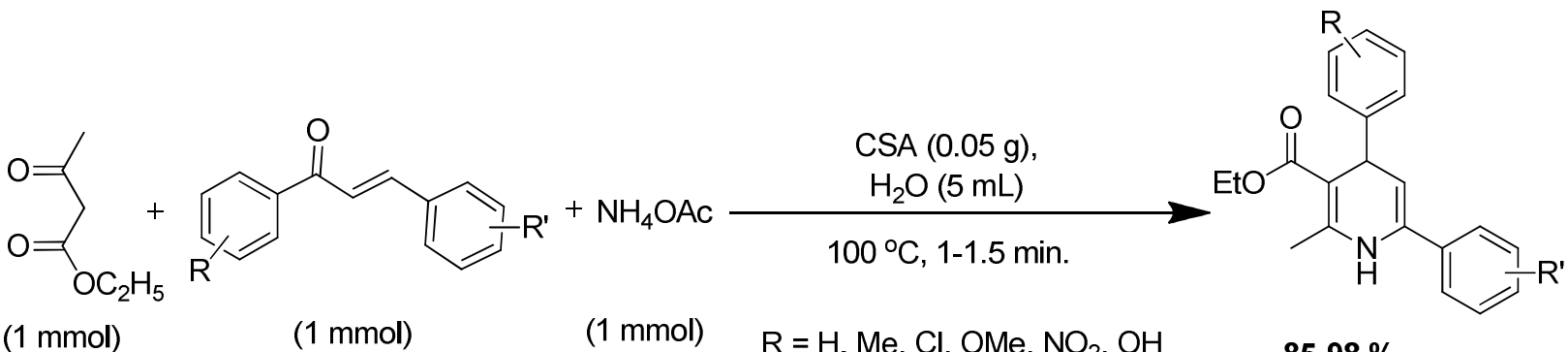

(1 $\mathrm{mmol})$

(1 mmol) $\mathrm{R}^{\prime}=\mathrm{H}, \mathrm{NO}_{2}, \mathrm{Cl}, \mathrm{Br}, \mathrm{OH}$

Scheme 7. Synthesis of 1,4-dihydropyridines derivatives catalyzed by CSA.

A simple and efficient protocol has been discovered by Mofakham and co-workers ${ }^{34}$ for the synthesis of 3,4-dihydroquinoxalin-2-amine, 4H-1,4-benzothiazin-2-amine and 1,6-dihydropyrazine-2,3-dicarbonitrile derivatives by utilizing various of amines, isocyanides and carbonyl compounds in the presence of catalytic amount of cellulose sulfuric acid (CSA) in ethanol at room temperature (Scheme 8). Various solvents such as water, dichloromethane (DCM), chloroform, acetonitrile (ACN), benzene, tetrahydrofuran (THF), methanol and ethanol were examined in the synthesis of synthesis of 2-(2-bromophenyl)-N-cyclohexyl-2(phenylamino)acetamide, by authors for optimization of the reaction condition, but only ethanol and methanol gave excellent results compare to others. In addition, catalysts such as $\mathrm{TsOH} . \mathrm{H}_{2} \mathrm{O}$,

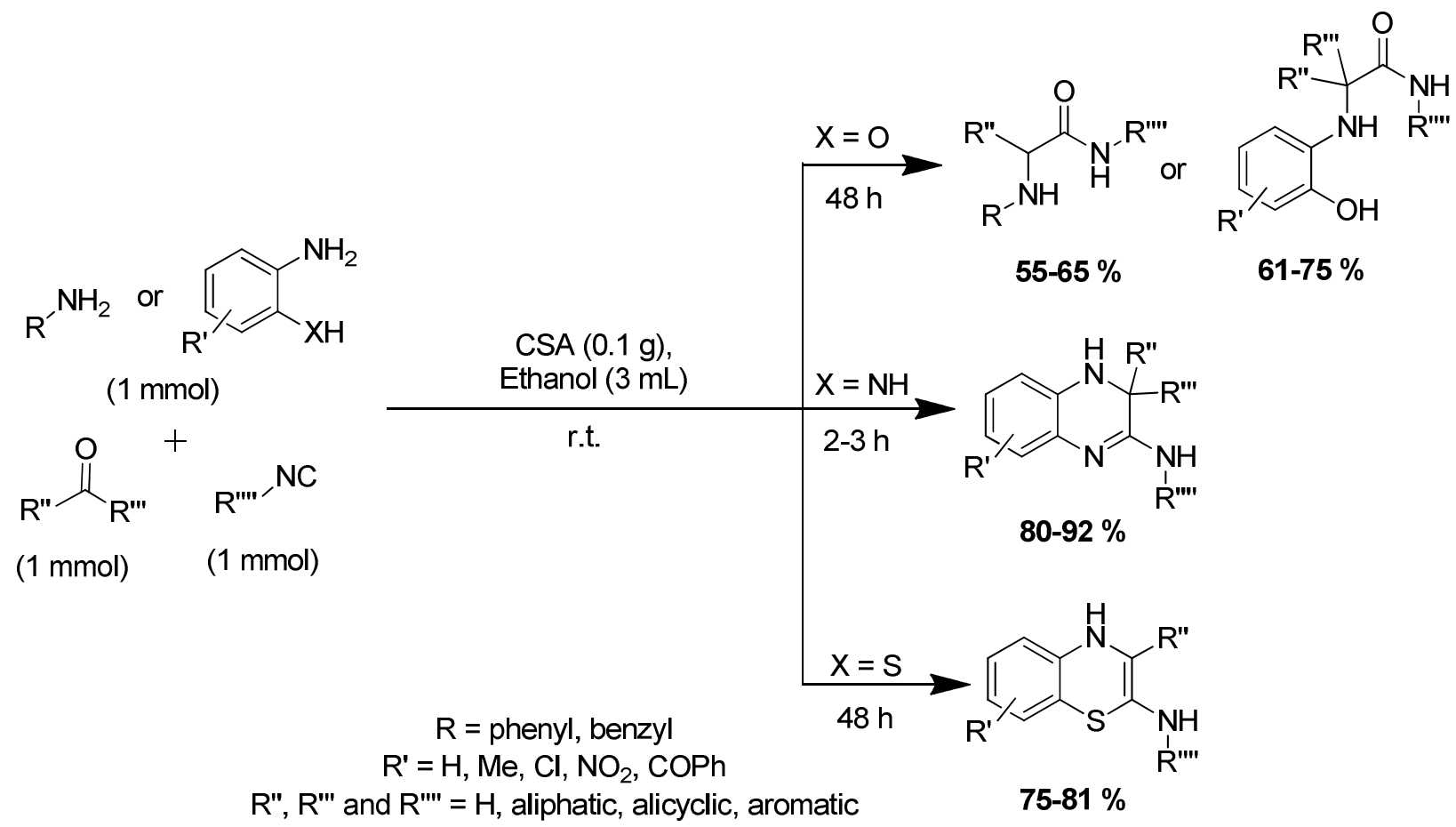

Scheme 8. Synthesis of 3,4-dihydroquinoxalin-2-amine and 4H-1,4-benzothiazin-2-amine. 
$\mathrm{HCl}$, silica sulfuric acid (SCA) and xanthane sulfuric acid (XSA) were employed in same reaction, but they were not efficient as like CSA. Here, 1,6-dihydropyrazine-2,3-dicarbonitriles were efficiently synthesized by this protocol using 2,3-diaminomaleonitrile, isocyanides and carbonyl compounds in the presence of catalytic amount of cellulose sulfuric acid (CSA) in ethanol at room temperature, which afforded excellent yield of the products (Scheme 9).<smiles>N#CC(N)=C(N)C#N</smiles>

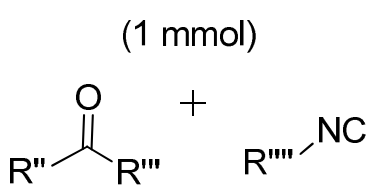

(1 $\mathrm{mmol}) \quad(1 \mathrm{mmol})$

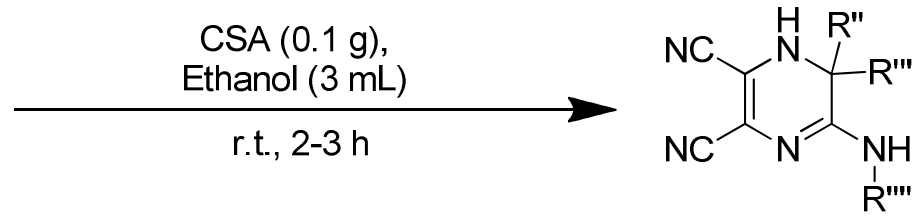

$87-95 \%$

R", R"' and R"' = H, aliphatic, alicyclic, aromatic

Scheme 9. Synthesis of 1,6-dihydropyrazine-2,3-dicarbonitrile derivatives catalyzed by CSA.

Rajack et al. ${ }^{35}$ have described an environmentally friendly procedure for the synthesis of 3,4dihydropyrimidin-2 $(1 H)$-ones/-thiones via Biginelli condensation in the presence of cellulose sulfuric acid (CSA) in water at $100{ }^{\circ} \mathrm{C}$ to afford good yield of the products (Scheme 9). In this care, $0.04 \mathrm{~g}$ CSA gave poor results as compared to $0.05 \mathrm{~g}$ of CSA. Various organic solvents such as ethanol, methanol, acetonitrile, dioxane and toluene showed poor results as compared to water in terms of the yield of the product. In addition, $N$-dihydro pyrimidinonedecahydroacridine-1,8dione derivatives have been synthesized in excellent yield through the Hantzsch type condensation of 5-ethoxycarbonyl-4-(4-aminophenyl)-6-methyl-3,4-dihydropyrimidine-2(1H)one, dimedone and aromatic aldehydes in acetonitrile under reflux conditions (Scheme 10). To optimize the reaction condition, the authors have carried out various catalysts such as Dowex, silica sulfuric acid (SSA), Amberlyst-15 and $p$-TSA in both Biginelli as well as for Hantzsch type condensation reaction. However, all these catalysts did not show better results as compared to CSA. Various 3,4-dihydropyridinones and acridine derivatives were efficiently synthesized demonstrating wide synthetic utility of this method.

An environment friendly protocol for the synthesis of N-substituted pyrroles through the onepot condensation reaction of 2,5-hexandione with amines and diamines in the presence of catalytic amount of cellulose sulfuric acid (CSA) at room temperature under solvent-free conditions have been demonstrated by Rahmatpour ${ }^{36}$ (Scheme 11). Short reaction times and high product yields make this method a highly useful synthetic protocol. To optimize reaction conditions the author carried out this reaction with various solvents such as dichloromethane (DCM), chloroform, carbon tetrachloride and acetonitrile, however the use of these solvents gave less efficient results than the solvent-free conditions. There was an observed significant 
improvement in the rate of the reaction and the yields of the products, when the reactions were carried out using CSA as compared with the classical acidic catalysts such as hydrochloric acid, ${ }^{37}$ sulfuric acid, ${ }^{38}$ and $p$-toluenesulfonic acid (p-TSA). ${ }^{39}$ In addition, after completion of the reaction, the CSA could be recovered and reused several times while the conventional catalysts could not be recovered.

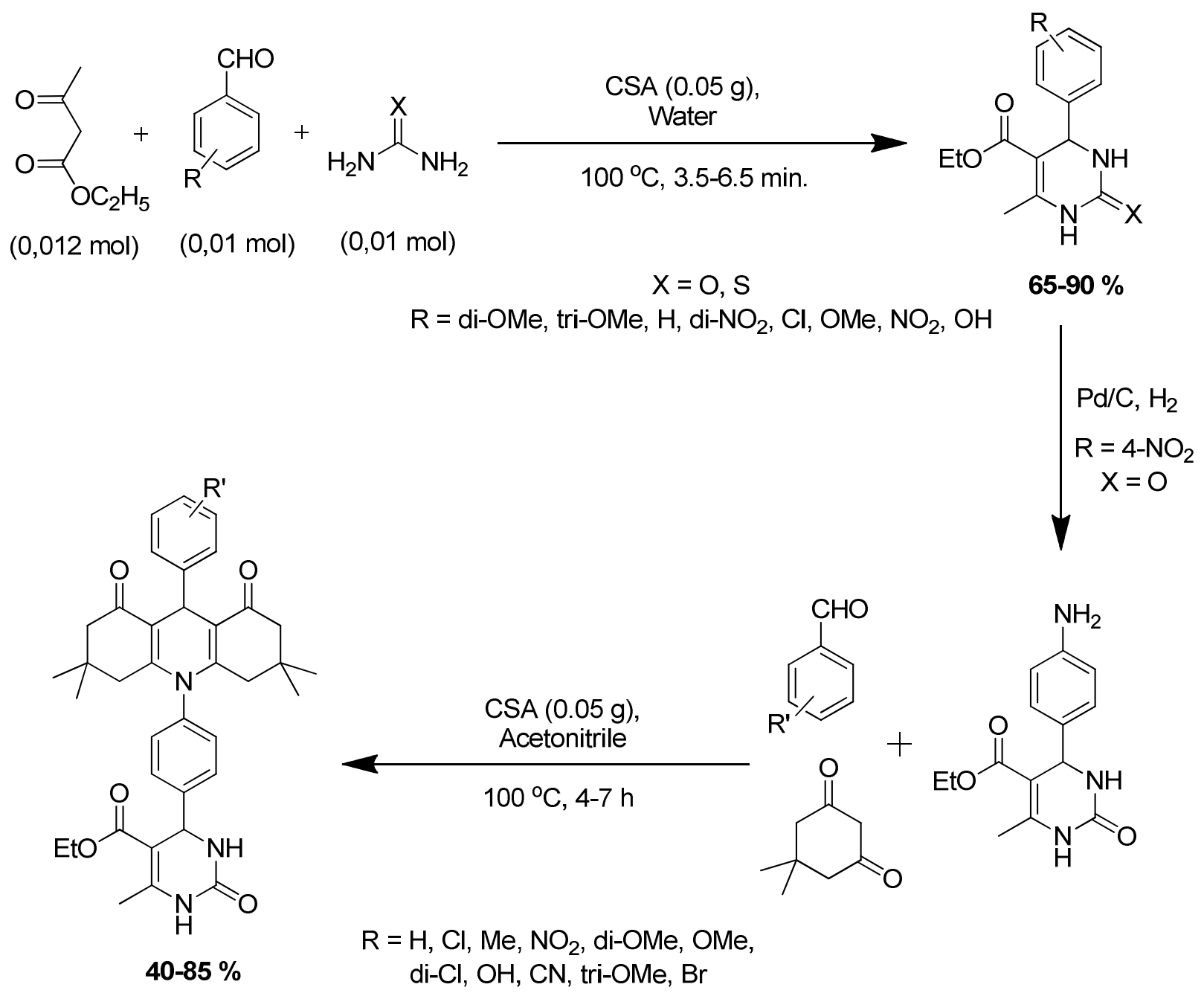

Scheme 10. Synthesis of 3,4-dihydropyrimidin-2(1H)-ones/-thiones and decahydroacridine1,8-dione derivatives catalyzed by CSA. 


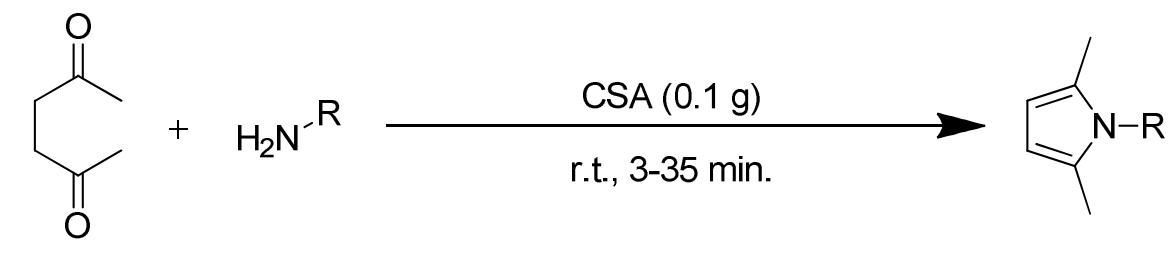

$(1 \mathrm{mmol}) \quad(1 \mathrm{mmol})$

$$
\mathrm{R}=\text { alkyl, aryl, cyclohexyl, naphthyl }
$$

$89-99 \%$

Scheme 11. Synthesis of $N$-substituted pyrroles catalyzed by CSA.

Shaabani et $a l^{40}$ has developed a synthesis of quinoline derivatives via Friedlander condensation reaction of 2-aminoarylketone with an activated $\mathrm{CH}$-acid such as cyclic or acyclic $\beta$-diketones or cyclic ketones in the presence of catalytic amount of cellulose sulfuric acid (CSA) and starch sulfuric acid (SSA) in excellent yields within a short period of time under solvent-free conditions at $100{ }^{\circ} \mathrm{C}$ (Scheme 12). Here, the efficiency of CSA and SSA towards this reaction<smiles>Nc1cc[R]cc1C(=O)c1ccccc1</smiles>

(1 mmol)<smiles>[R7]CC([R])=O</smiles>

$(1.2 \mathrm{mmol})$

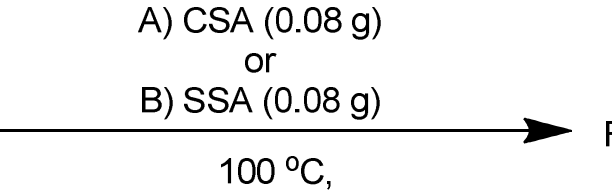

A) $15-30 \mathrm{~min}$.

B) $25-40 \mathrm{~min}$.

$\mathrm{R}=\mathrm{H}, \mathrm{Cl} \mathrm{R}^{\prime}=\mathrm{Me}$

$\mathrm{R}^{\prime \prime}=\mathrm{Me}, \mathrm{OMe}, \mathrm{OEt}$<smiles>[R]C=Cc1c(-c2ccccc2)nc([R])c([R7])c1-c1ccccc1</smiles>

A) $82-95 \%$ B) $81-95 \%$<smiles></smiles>

(1 mmol)<smiles>Nc1c[R]ccc1C(=O)c1ccccc1</smiles>

(1 mmol)
(1.2 mmol)<smiles>O=C1CCCC1</smiles>

(1.2 mmol)

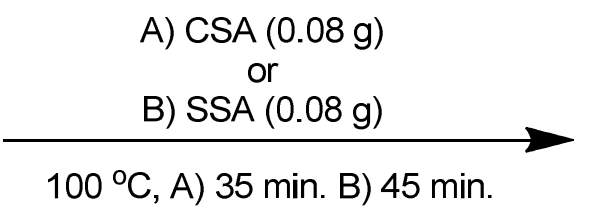

$\mathrm{R}=\mathrm{H}, \mathrm{Cl}$

A) CSA (0.08 g)

or

B) SSA (0.08 g)

$100^{\circ} \mathrm{C}$

A) $40-55 \mathrm{~min}$.

B) $55-70 \mathrm{~min}$.

$\mathrm{R}=\mathrm{H}, \mathrm{Cl}$

$\mathrm{n}=1,2$<smiles>[R]=C1C=Cc2nc3c(c(-c4ccccc4)c2C1=O)CC(C)(C)CC3=O</smiles>

A) $70-80 \%$

B) $75-80 \%$

Scheme 12. Synthesis of quinoline derivatives catalyzed by CSA. 
<smiles>[R]C(=O)C([R])=O</smiles>

(1 mmol)

(1 $\mathrm{mmol})$

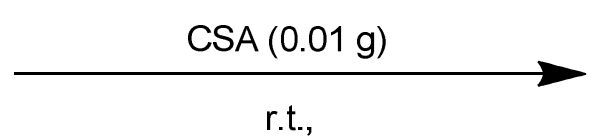

A) Ethanol, 1-24 h

B) Water, 2-24 h

$\mathrm{R}=\mathrm{H}, \mathrm{Cl}, \mathrm{Me}, \mathrm{NO}_{2}, \mathrm{PhCO}$

$\mathrm{R}^{\prime}=\mathrm{Ph}, \mathrm{Me}, 4-\mathrm{OMe}-\mathrm{C}_{6} \mathrm{H}_{4}$<smiles>[R]C=Cc1cccc2nc([R])c([R])nc12</smiles>

A) $79-93 \%$

B) $50-83 \%$

Scheme 13. Synthesis of quinoxaline derivatives catalyzed by CSA.

A new and green method has been discovered by Liu et $a l^{43}$ for the synthesis of 5hydroxymethylfurfural (HMF) and 5-ethoxymethylfurfural (EMF) from fructose using cellulose sulfuric acid (CSA) as a bio-degradable catalyst (Scheme 14). Here, HMF was obtained in high yield $(93.6 \%)$ in dimethylsulfoxide (DMSO) for $45 \mathrm{~min}$. While, EMF was obtained in an excellent yield $(84.4 \%)$ by the etherification of HMF under the same reaction conditions. In addition, EMF could be also synthesized in good yield (72.5\%) directly from the fructose through one-pot reaction, which included that the dehydration of fructose into HMF, followed by etherification of HMF into EMF.

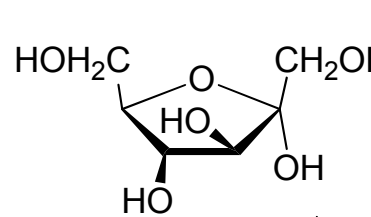

$(1 \mathrm{mmol})$

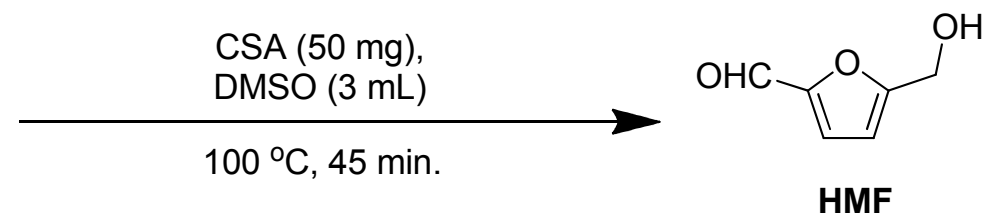

$93.6 \%$

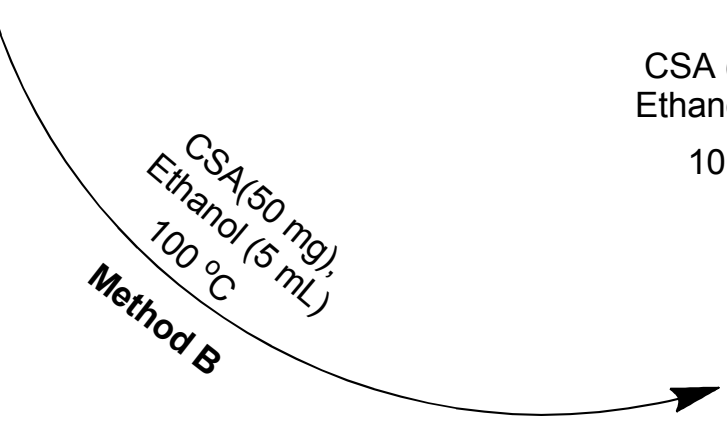

CSA (50 mg), Ethanol $(5 \mathrm{~mL})$

$100{ }^{\circ} \mathrm{C}$

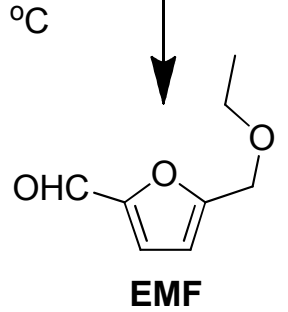

Method A: $84.4 \%$ Method B: $72.5 \%$

Scheme 14. Synthesis of HMF and EMF catalyzed by CSA.

Shaabani and co-workers ${ }^{44}$ have also developed a high yielding synthesis of imidazoazine derivatives through the one-pot three-component condensation reaction of aldehydes, 2aminoazine and isocyanides in the presence of catalytic amount of cellulose sulfuric acid (CSA), as an effective bio-supported catalyst in methanol at room temperature (Scheme 15). The results 
showed that the efficiency and the yield of the product in methanol were higher than those obtained in other solvents like water, ethanol, dichloromethane, toluene, acetonitrile and solventfree condition. This reaction was also carried out in the presence of various acids such as Amberlyst-21, Montmorillonite-K10, $\mathrm{CSA}, \mathrm{HCl}, \mathrm{H}_{2} \mathrm{SO}_{4}$, acetic acid and $\mathrm{AlCl}_{3}$. However the best yield was obtained with CSA.

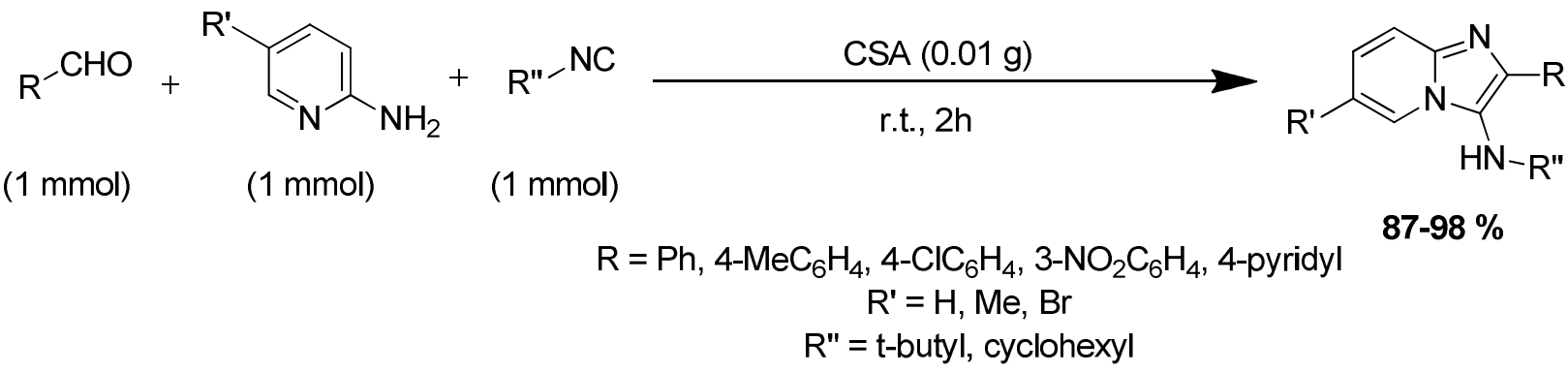

Scheme 15. Synthesis of imidazoazine derivatives catalyzed by CSA.

Shaterian and co-workers ${ }^{45}$ have disclosed that the primary, secondary and tertiary alcohols as well as phenols and naphthols were effectively converted into their corresponding trimethylsilyl ethers in excellent yield by using with hexamethyldisilazane (HMDS) in the presence of catalytic amount of cellulose sulfuric acid (CSA) at room temperature with short reaction times (Scheme 16).

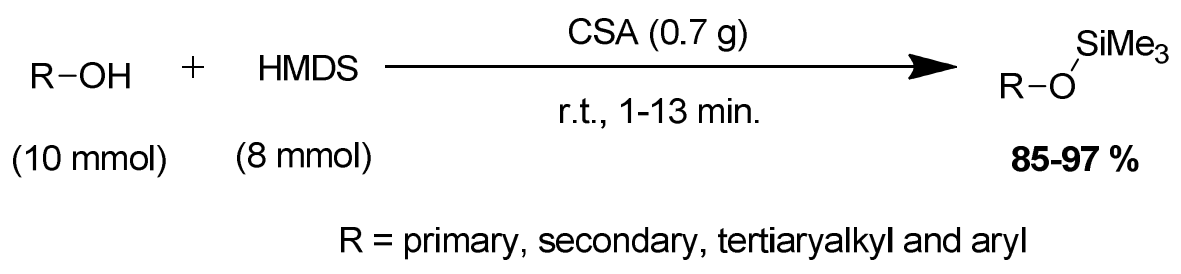

Scheme 16. Silylation of alcohols and phenols catalyzed by CSA.

Nemati et $a l .{ }^{46}$ have developed a green and mild protocol for the diazotization and azidation of various aromatic amines by using sodium nitrite and sodium azide respectively in the presence of catalytic amount of CSA at room temperature, which afforded excellent yield of the products (Scheme 17). In addition, the wide range of arylamines containing electron-withdrawing groups and electron-releasing groups were efficiently converted into the corresponding aryl azides with excellent yields make this protocol environmentally friendly. There was an observed significant improvement in the rate of the reaction and the yields of the products, with this protocol as compared to the classical synthetic method of aryl azides. 


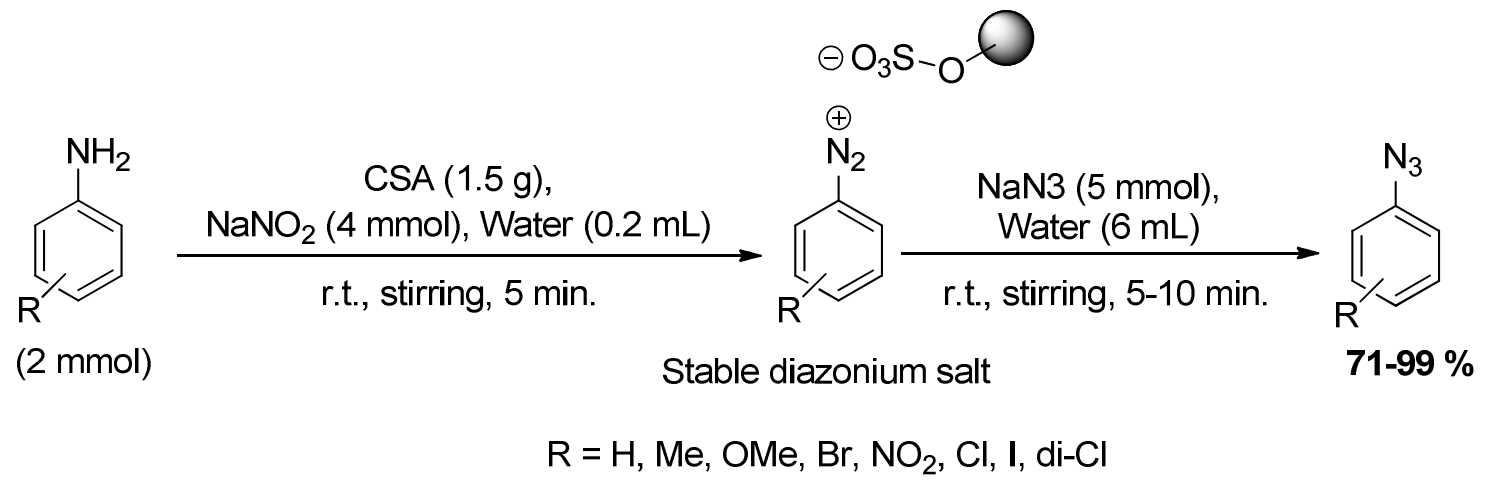

Scheme 17. Diazotization and azidation by using CSA.

A green and environmentally friendly method for the synthesis of 1-oxohexahydroxanthene derivatives in higher yields was developed by Karma and co-workers ${ }^{47}$ using ortho-hydroxy benzaldehydes and substituted 1,3-hexanediones in the presence of a catalytic amount of CSA at room temperature (Scheme 18). The best results were obtained using $0.08 \mathrm{~g}$ of catalyst, while with lower amounts, or in the absence of a catalyst, lower yields of the products resulted. For comparison, the authors carried out this reaction with various catalysts such as methanesulfonic acid, silica sulfuric acid and sulfuric acid in acetic acid. However, in such cases the yield of the products was very low compared to CSA.
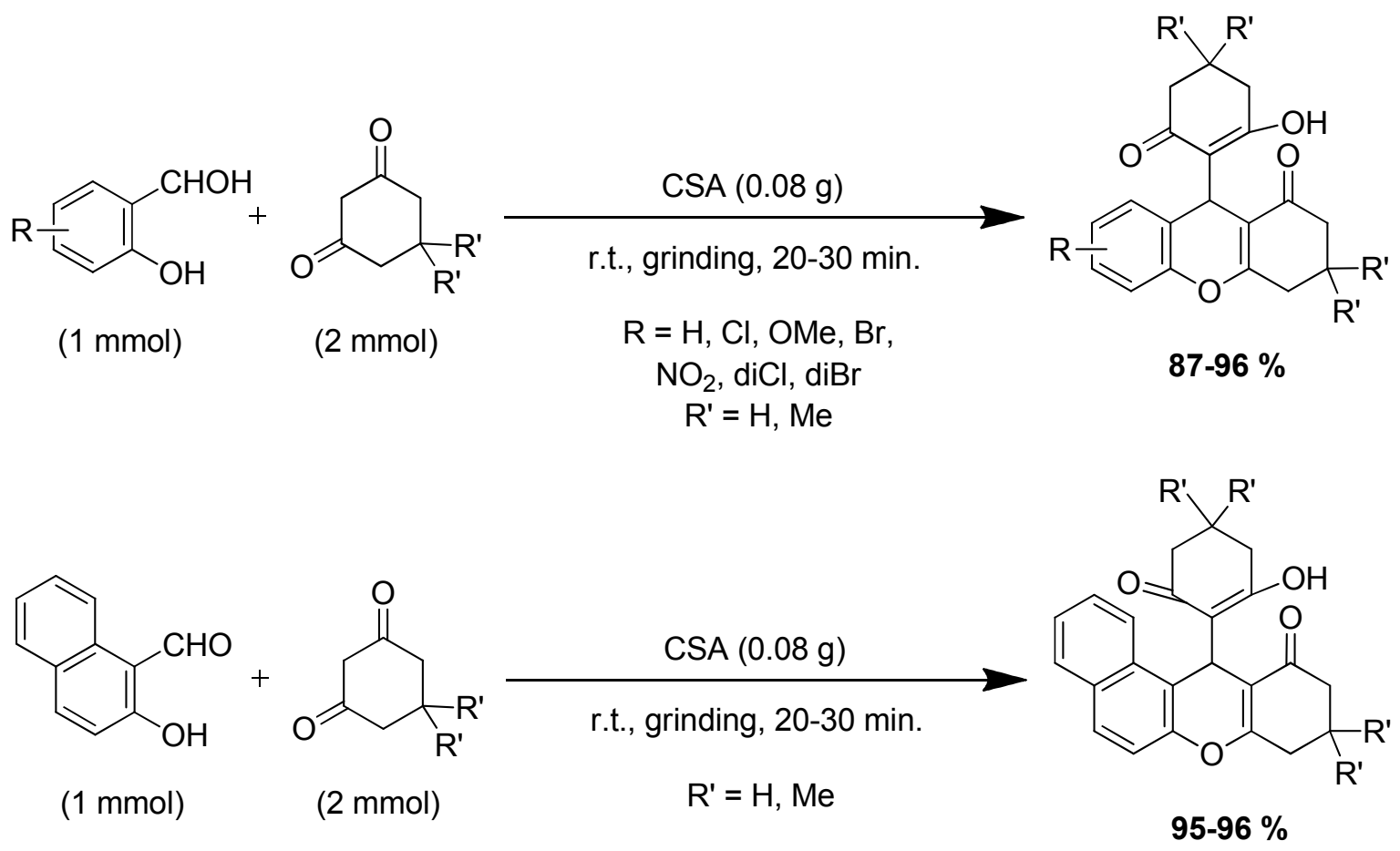

Scheme 18. Synthesis of 1-oxo-hexahydroxanthene derivatives catalyzed by CSA. 
Kuarm et $a l .{ }^{48}$ have described an efficient and environment friendly process for the synthesis of quinoxaline derivatives through the condensation reaction of the 2,1,3-benzothiadiazole-4,5diamine and 3-( $\alpha$-bromoacetyl)-coumarins in the presence of cellulose sulfuric acid (CSA) by grinding in a mortar and pestle at room temperature in excellent yields with high purity (Scheme 19). Various catalysts such as silica sulfuric acid, methanesulfonic acid and sulfuric acid in acetic acid were also employed in this reaction for comparison study; however those are not so efficient as CSA.<smiles>[R]=Cc1ccc2oc(=O)c(C(=O)CBr)cc2c1</smiles>

(3 mmol)<smiles>Nc1ccc2nsnc2c1N</smiles>

(3 mmol)

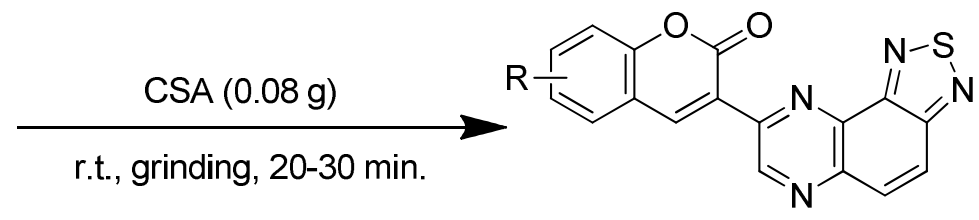

$\mathrm{R}=\mathrm{H}, \mathrm{Cl}, \mathrm{Me}, \mathrm{Br}$

$89-96 \%$

Scheme 19. Synthesis of quinoxaline derivatives catalyzed by CSA.

Reddy et $a l .{ }^{49}$ have discovered one-pot synthesis of 3,4-dihydropyrimidin-2(1H)-ones/thiones by utilizing various aldehydes, $\beta$-ketoesters and urea/thiourea in the presence of cellulose sulfuric acid (CSA) in ethanol under reflux conditions to afford excellent yield (Scheme 20). Various solvents such as ethanol, methanol, dichloromethane, acetonitrile and toluene were also employed in this reaction for comparative study, among those ethanol shows better efficiency in terms of the yield of the product.

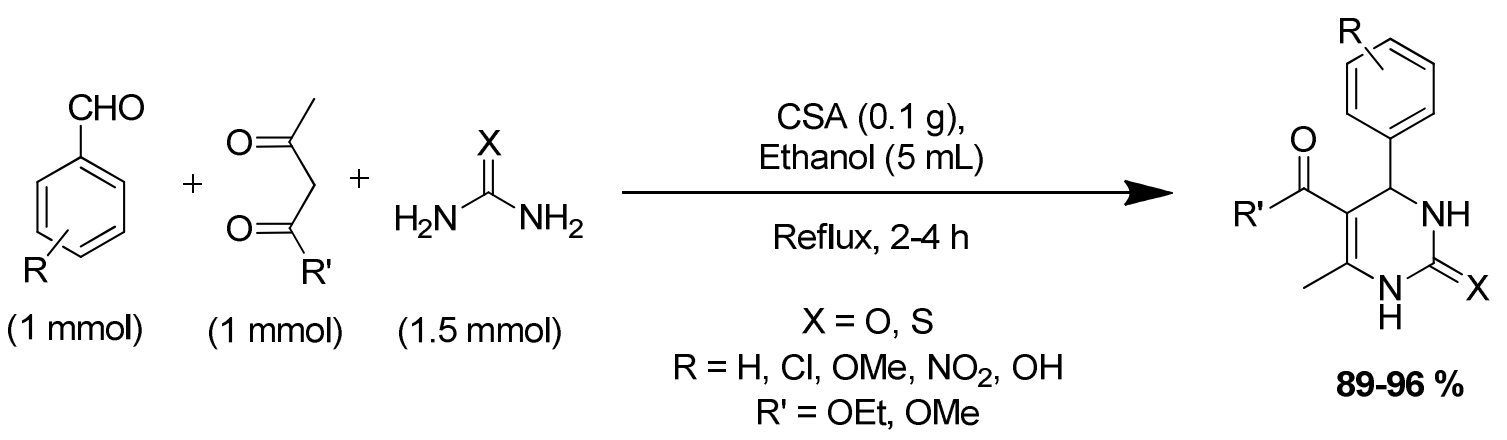

Scheme 20. Synthesis of 3,4-dihydropyrimidin-2(1H)-ones/thiones catalyzed by CSA.

Oskooie and co-workers ${ }^{50}$ have discovered an efficient protocol for the synthesis of $\beta$ acetamido ketone derivatives in high yield through the one-pot, four-component condensation of benzaldehyde, dimedone, acetyl chloride and acetonitrile in the presence of cellulose sulfuric acid (CSA) in acetonitrile under reflux condition (Scheme 21. Here, the synthesis of $N$-[(4,4dimethyl-2,6-dioxocyclohexyl)phenyl)methyl]acetamide was selected as the model reaction. To investigate the effect of catalyst amount on the yield of the reaction the authors have carried out 
model reaction with different amount of catalyst. The results show that the optimum amount of catalyst was $0.01 \mathrm{~g}$. The model reaction was performed in the presence of the same amounts of various catalysts such as silica sulfuric acid (SSA), $p$-toluenesulfonic acid ( $p$-TSA), sulfamic acid, $\mathrm{SbCl}_{3}$ and various heteropoly acids, but they didn't work efficiently as like CSA.

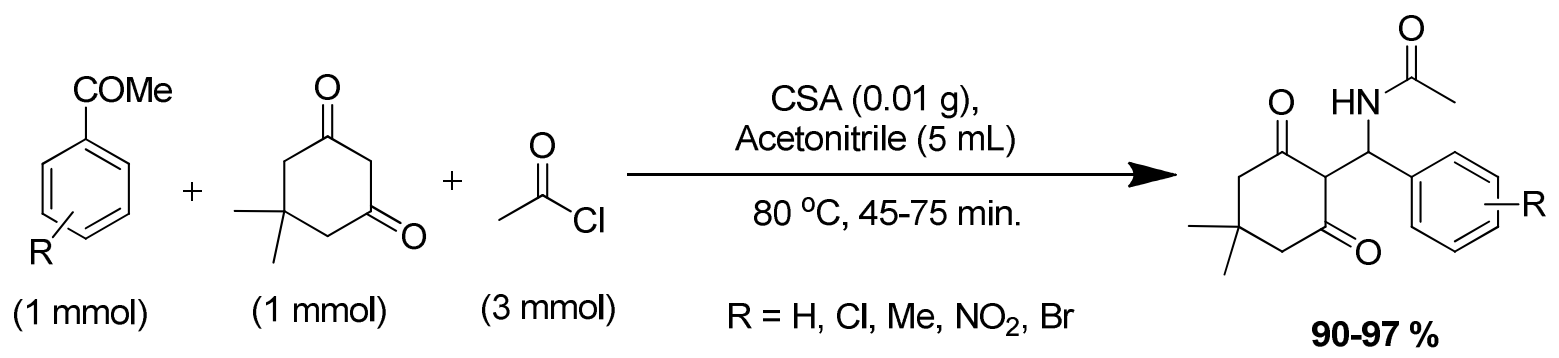

Scheme 21. Synthesis of $\beta$-acetamido ketone derivatives catalyzed by CSA.

An efficient and green protocol for the synthesis of 2-substituted benzimidazoles has been discovered by Kuarm and co-workers ${ }^{51}$ via condensation of 2,1,3-benzothiadiazole-4,5-diamine with different aldehydes in the presence of the catalytic amount of the cellulose sulfuric acid (CSA) under solvent-free conditions by grinding in a mortar and pestle at room temperature (Scheme 22). The efficiency of the cellulose sulfuric acid compared to various sulfur analog acidic catalysts such as silica sulfuric acid (SSA), $p$-Toluenesulfonic acid (p-TSA) and sulfuric acid in acetic acid were also examined. However, cellulose sulfuric acid is more efficient and superior over other acidic catalysts with respect to reaction time and yield.

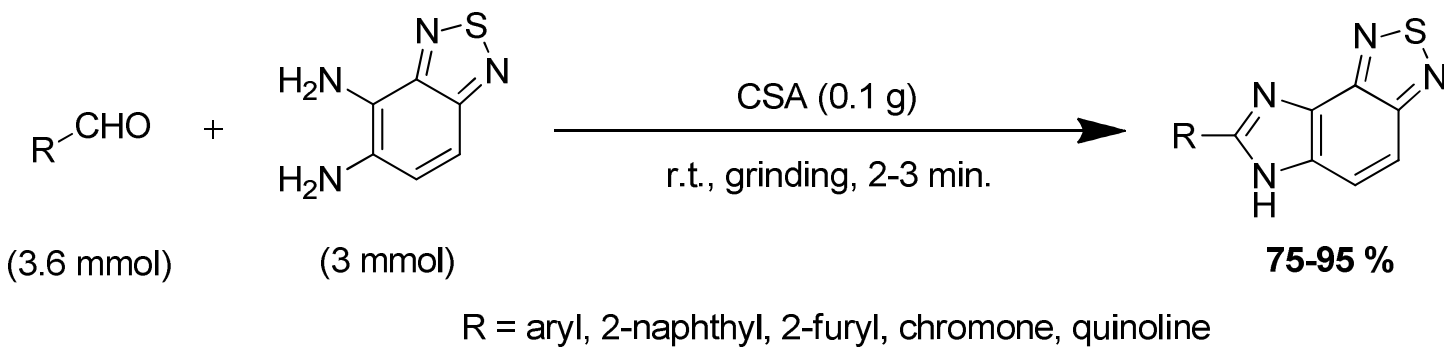

Scheme 22. Synthesis of 2-substituted benzimidazoles derivatives catalyzed by CSA.

Sadaphal et al. $^{52}$ have discovered the synthesis of bis(indolyl)methane derivatives by using indole and various aldehydes in the presence of cellulose sulfuric acid (CSA) as a biodegradable catalyst at room temperature under solvent-free condition (Scheme 23). 


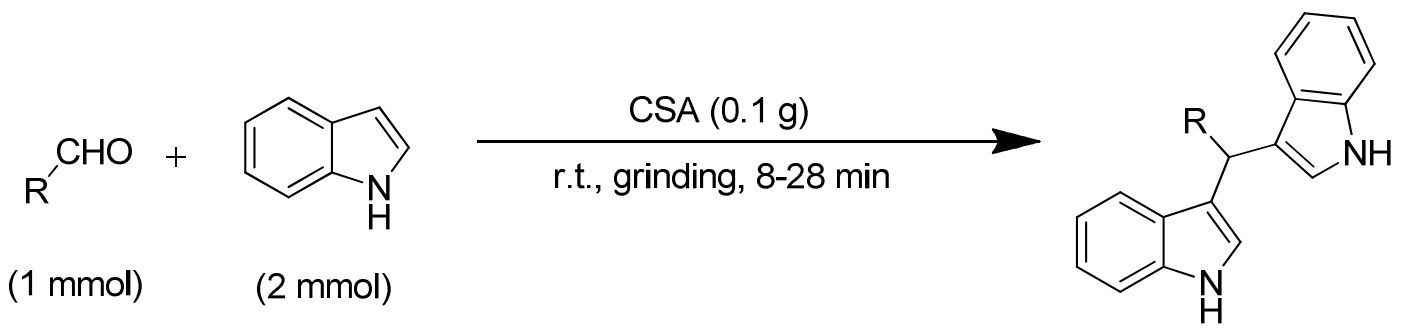

$85-95 \%$

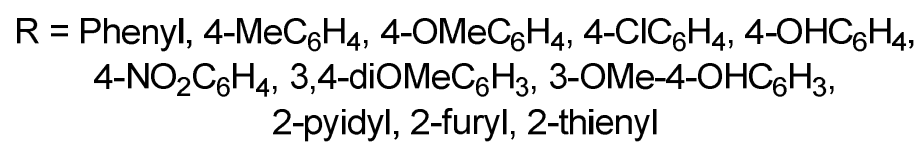

Scheme 23. Synthesis of bis(indolyl)methane derivatives catalyzed by CSA.

A simple and environmentally friendly procedure has been developed by Shelke et al. ${ }^{53}$ for the synthesis of 2,4,5-triarylimidazole derivatives through the three-component condensation of benzil/benzoin, various aldehydes and ammonium acetate in the presence of a catalytic amount of bio-supported cellulose sulfuric acid (CSA) under microwave irradiation and solvent-free conditions to afford excellent yield of the products (Scheme 24). Different acid catalysts such as $\mathrm{HgCl}_{2}, \mathrm{SnCl}_{2} .2 \mathrm{H}_{2} \mathrm{O}, \mathrm{H}_{2} \mathrm{SO}_{4}, \mathrm{HCl}$, clays EPZG, clay EPZ 10 and CSA were employed in this transformation by the authors for comparative study. The shorter reaction rate and the better yield were obtained with CSA compared to others. It is also noted that solvent-free conditions show better results as compared to reaction in solvents.

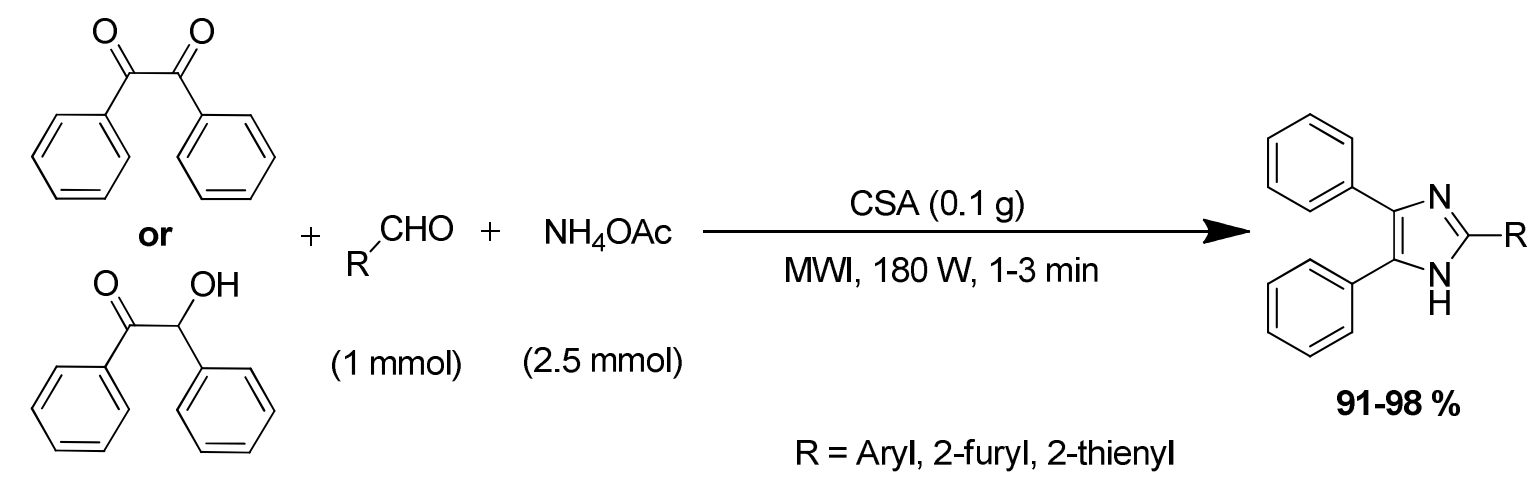

$(1 \mathrm{mmol})$

Scheme 24. Synthesis of 2,4,5-triarylimidazole derivatives catalyzed by CSA.

Mosaddegh and co-workers ${ }^{54}$ have reported the environmentally friendly and one-pot multicomponent synthesis of 4,4'-arylmethylene-bis(3-methyl-1-phenyl-1 $H$-pyrazol-5-ol) through tandem Knoevenagel-Michael reaction of different aryl aldehydes and 5-methyl-2-phenyl-2,4dihydro-3H-pyrazol-3-one in the presence of a catalytic amount of cellulose sulfuric acid (CSA) 
in water-ethanol as a green solvent media under reflux conditions to afforded excellent yield of the products (Scheme 25).

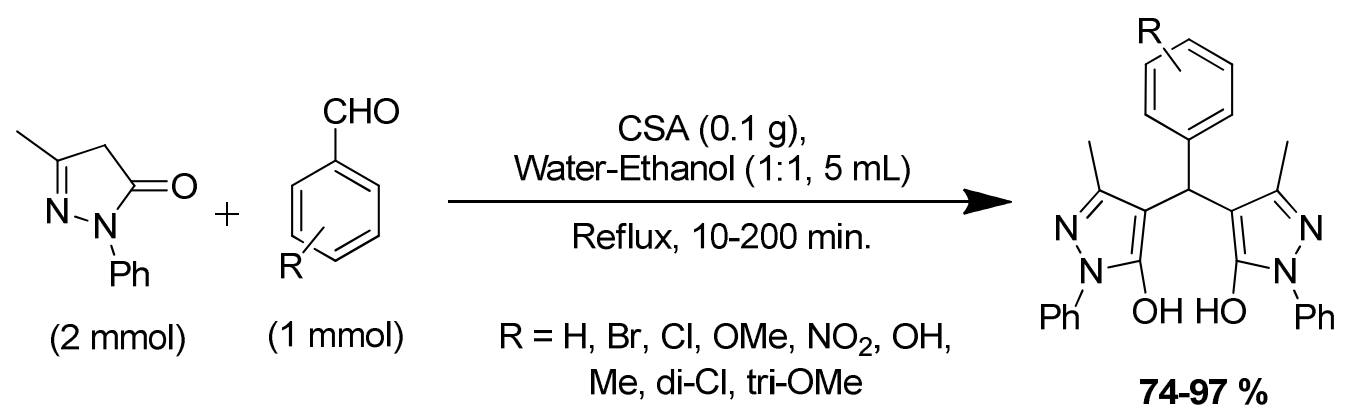

Scheme 25. Synthesis of 4,4'-arylmethylene-bis(3-methyl-1-phenyl-1H-pyrazol-5-ol) derivatives catalyzed by CSA.

\section{Starch Sulfuric Acid (SSA)}

The SSA can be prepared by magnetically stirring a suspension of $5.00 \mathrm{~g}$ of starch in $20 \mathrm{ml}$ of $n$ hexane, and adding $1.00 \mathrm{~g}$ of chlorosulfonic acid $(9 \mathrm{mmol})$ dropwise at $0{ }^{\circ} \mathrm{C}$ over $2 \mathrm{~h} . \mathrm{HCl}$ gas is evolved from the reaction vessel immediately. After the addition is complete, the mixture is stirred for $2 \mathrm{~h}$ at room temperature. The mixture is then filtered and washed with $30 \mathrm{ml}$ acetonitrile and dried at room temperature to afford $5.25 \mathrm{~g}$ of starch sulfuric acid as a white powder. SSA is non-explosive, non-hygroscopic and stable at room temperature. ${ }^{59}$

Organic transformations using SSA have many advantages such as a simple work-up process, and inexpensive catalyst, environmentally friendly, excellent yield of the products with high purity, shorter reaction time and solvent-free reaction conditions. The SSA is a solid, heterogeneous catalyst, which can be easily recovered after completion of the reaction and reused many times without loss of their activity.

\subsection{Various organic transformations catalyzed by SSA}

Rezaei and co-workers ${ }^{55}$ have developed environmentally benign protocol for the synthesis of $\alpha, \alpha^{\prime}$-benzylidene bis(4-hydroxycoumarin) derivatives by employing various aromatic aldehydes with 4-hydroxycoumarin under solvent-free condition at $80{ }^{\circ} \mathrm{C}$ to afforded excellent yield of the products (Scheme 25). The reaction was also examined by the authors in ethanol, water, chloroform and toluene as solvents. However, in the presence of solvents the reaction becomes sluggish. In addition, it is noted that below $80{ }^{\circ} \mathrm{C}$, the reaction could not proceed efficiently and gives a lower yield of the products. Both an electron-donating or electron-withdrawing substituents on the aromatic ring gave efficient results. Compared with the conventional catalysts 
such as $\mathrm{p}-\mathrm{TsOH},{ }^{56} \mathrm{HCl},{ }^{57}$ and acetic acid, ${ }^{58}$ the SSA were showed better results in terms of the yields of the products and time of the reaction.

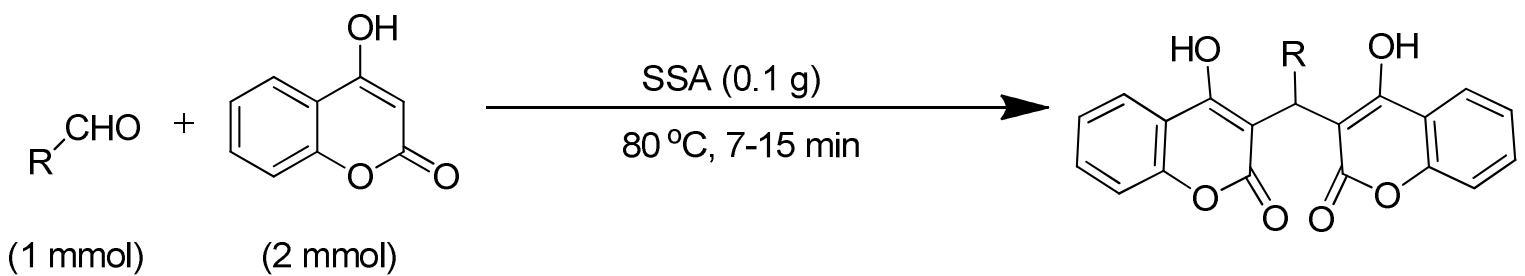

\section{$80-90 \%$}

$$
\begin{gathered}
\mathrm{R}=\text { Phenyl, 4- }-\mathrm{MeC}_{6} \mathrm{H}_{4}, 3,4-\mathrm{diOMeC} \mathrm{CH}_{3}, 4-\mathrm{ClC}_{6} \mathrm{H}_{4}, 2-\mathrm{ClC}_{6} \mathrm{H}_{4} \text {, } \\
\text { 4-OHC } \mathrm{OH}_{4}, 4-\mathrm{OMeC}_{6} \mathrm{H}_{4}, 4-\mathrm{NO}_{2} \mathrm{C}_{6} \mathrm{H}_{4}, 3-\mathrm{NO}_{2} \mathrm{C}_{6} \mathrm{H}_{4}, \\
\text { 4- } \mathrm{NMe}_{2} \mathrm{C}_{6} \mathrm{H}_{4}, 3-\mathrm{BrC}_{6} \mathrm{H}_{4}, 2 \text {-furyl, } \mathrm{CH}=\mathrm{CHC}_{6} \mathrm{H}_{4}
\end{gathered}
$$

Scheme 25. Synthesis of $\alpha, \alpha^{\prime}$-benzylidene bis(4-hydroxycoumarin) derivatives catalyzed by SSA

Rezaei et al. ${ }^{59}$ have developed the one-pot multi-components synthesis of 3,4dihydropyrimidinone derivatives by using aldehydes, $\beta$-keto esters and urea/thiourea in the presence of the starch sulfuric acid (SSA) as an environment friendly polymer-based solid acid catalyst under solvent-free condition (Scheme 26). Various solvents such as acetonitrile, tetrahydrofuran (THF), ethanol and water were also examined by the authors in this reaction, however solvent-free condition shows better results. Lower yields of the products were observed at lower temperature.

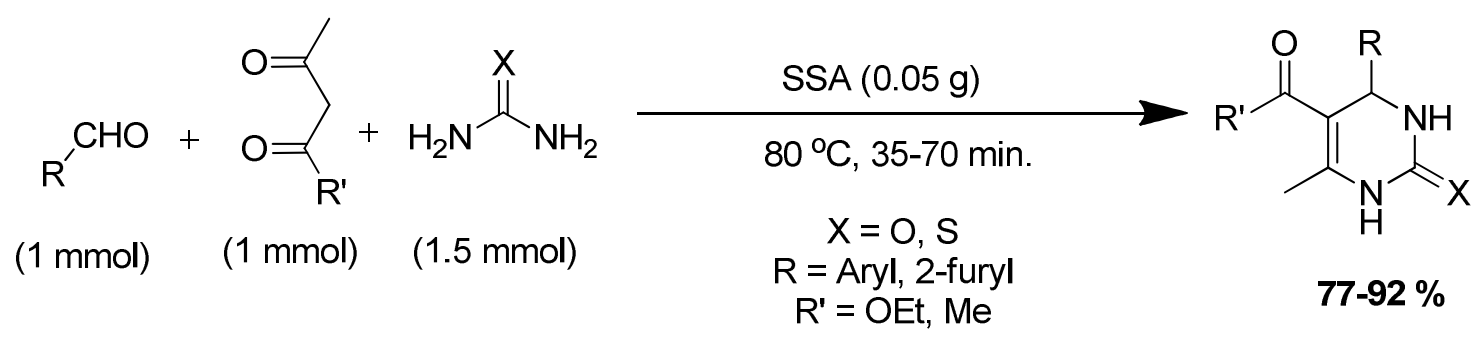

Scheme 26. Synthesis of 3,4-dihydropyrimidinone catalyzed by SSA.

Hatamjafari ${ }^{60}$ has discovered an efficient method for the synthesis of 1,5-diaryl- $1 H$-pyrazole derivatives by employing phenylhydrazine and Baylis Hillman adducts in the presence of starch sulfuric acid (SSA) as reusable catalyst in 1,2-dicloroethane (DCE), which afforded excellent yield of the products (Scheme 27). In addition, Baylis Hillman adducts were prepared by the reaction of methyl or ethyl vinyl ketone and various benzaldehydes benzaldehydes. Here, $0.05 \mathrm{~g}$ of SSA was sufficient to catalyze the reaction effectively. Various solvents such as water, methanol, ethanol, acetonitrile, tetrahydrofuran (THF), and 1,2-dichloroethane (DCE) were used 
in this reaction by the authors to optimize the reaction condition. But, only the DCE gave excellent yields of the products.

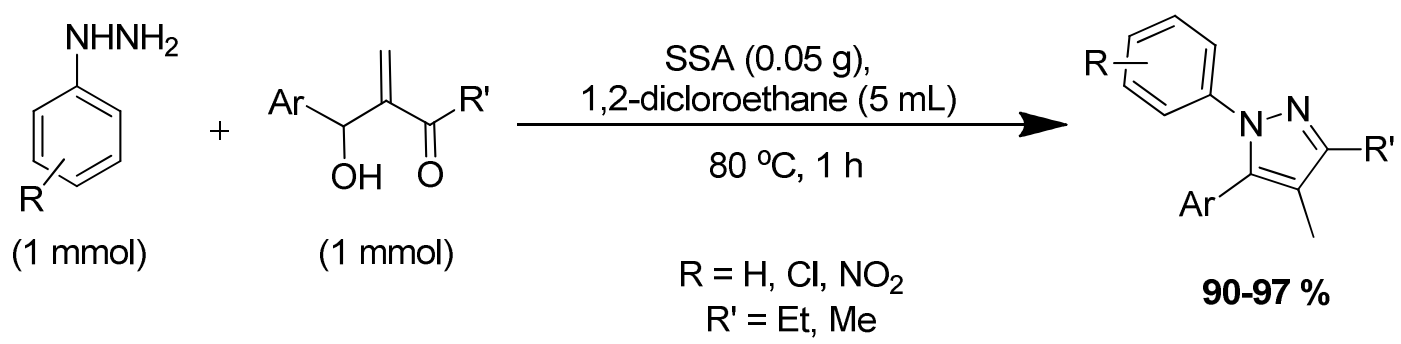

Scheme 27. Synthesis of 1,5-diaryl-1H-pyrazole derivatives catalyzed by CSA.

\section{Conclusions}

In the recent years, several new heterogeneous catalyzed organic processes have been reported in the field of organic chemistry, which added new "environment friendly and green" tools for the synthesis of valorous molecules. In recent years, cellulose sulfuric acid (CSA) and starch sulfuric acid (SSA) have been developed as biodegradable catalysts for improving selectivity, purity and high yield of the organic compounds. Particularly, CSA is widely used in a wide range of organic syntheses efficiently. Besides the great advances that have been obtained so far, most research in the development of new CSA and SSA catalyzed organic synthesis of pharmaceutical interest is required. Due to this urgency, we will definitely see an increasing number of novel protocols for the synthesis of various organic compounds catalyzed by these solid heterogeneous catalysts.

\section{Acknowledgements}

The authors are thankful to the Department of Chemistry, Gujarat University, Ahmedabad, for providing the necessary facilities. UGC-Info net \& INFLIBNET Gujarat University are acknowledged for providing the e-source facilities. R.H.V. is thankful to UGC-BSR (F.774/2007 (BSR)) for financial assistance.

\section{References}

1. Jiang, H. Y.; Yang, C. F.; Li, C.; Fu, H. Y.; Chen, H.; Li, R. X.; Li, X. J. Angew. Chem. Int. Ed. 2008, 47, 9240-9244. http://dx.doi.org/10.1002/anie.200801809

2. Jiang, H. Y.; Sun, B.; Zheng, X. X.; Chen, H. Appl. Catal., A: Gen. 2012, 421, 86-90. 
http://dx.doi.org/10.1016/j.apcata.2012.02.002

3. Corma, A.; Garcia, H. Chem. Rev. 2003, 103, 4307-4366.

http://dx.doi.org/10.1021/cr030680z

4. Baleizao, C.; Garcia, H. Chem. Rev. 2006, 106, 3987-4043.

http://dx.doi.org/10.1021/cr050973n

5. Van Leeuwen, P. Homogeneous catalysis, Springer: Kluwer Academic, Netherlands, 2004; pp 1-401. http://dx.doi.org/10.1007/1-4020-2000-7_1

6. Sanz, R.; Miguel, D.; Martínez, A.; Alvarez-Gutierrez, J. M.; Rodriguez, F. Org. Lett. 2007, 9, 727-730. http://dx.doi.org/10.1021/o10631298

7. Farina, V. Adv. Synth. Catal. 2004, 346, 1553-1582. http://dx.doi.org/10.1002/adsc.20040417

8. Corma, A.; Garcia, H. Chem. Rev. 2003, 103, 4307-4366. http://dx.doi.org/10.1021/cr030680z

9. Hasaninejad, A.; Zare, A.; Shekouhy, M.; Ameri-Rad, J. Green Chem. 2011, 13, 958-964. http://dx.doi.org/10.1039/c0gc00953a

10. Zhang, Z.; Du, B.; Zhang, L. J.; Da, Y. X.; Quan, Z. J.; Yang, L. J.; Wang, X. C. RSC Adv. 2013, 3, 9201-9205. http://dx.doi.org/10.1039/c3ra41912f

11. Hasaninejad, A.; Kazerooni, M. R.; Zare, A. Catal. Today 2012, 196, 148-155. http://dx.doi.org/10.1016/j.cattod.2012.05.026

12. Vekariya, R. H.; Patel, H. D. Arkivoc 2014, DOI: 10.3998/ark.5550190.0016.100.

13. Siddiqui, Z. N.; Tarannum, S. C. R. Chim. 2013, 16, 829-837. http://dx.doi.org/10.1016/j.crci.2013.04.013

14. Chaudhari, P. S.; Salim, S. D.; Sawant, R. V.; Akamanchi, K. G. Green Chem. 2010, 12, 1707-1710. http://dx.doi.org/10.1039/c0gc00053a

15. Tamaddon, F.; Kargar-Shooroki, H.; Jafari, A. A. J. Mol. Catal. A: Chem. 2013, 368-369, 66-71. http://dx.doi.org/10.1016/j.molcata.2012.12.002

16. Karami, B.; Haghighijou, Z.; Farahi, M.; Khodabakhshi, S. Phosphorus, Sulfur Silicon Relat. Elem. 2012, 187, 754-761. http://dx.doi.org/10.1080/10426507.2011.616562

17. Amoozadeh, A.; Ahmadzadeh, M.; Kolvari, E. J. Chem. 2013, 2013, 1-6.

18. Breslow, R. Acc. Chem. Res. 1980, 13, 170-177. http://dx.doi.org/10.1021/ar50150a002

19. Wei, W. L.; Zhu, H. Y.; Zhao, C. L.; Huang, M. Y.; Jiang, Y. Y. React. Funct. Polym. 2004, 59, 33-39.

http://dx.doi.org/10.1016/j.reactfunctpolym.2003.10.004 
20. Crecchio, C.; Ruggiero, P.; Pizzigallo, M. Biotechnol. Bioeng. 1995, 48, 585-591. http://dx.doi.org/10.1002/bit.260480605

21. Huang, K.; Xue, L.; Hu, Y. C.; Huang, M. Y.; Jiang, Y. Y. React. Funct. Polym. 2002, 50, 199-203.

http://dx.doi.org/10.1016/S1381-5148(01)00103-1

22. Guibal, E. Prog. Polym. Sci. 2005, 30, 71-109. http://dx.doi.org/10.1016/j.progpolymsci.2004.12.001

23. Klemm, D.; Heublein, B.; Fink, H. P.; Bohn, A. Angew. Chem., Int. Ed. 2005, 44, 3358-3393. http://dx.doi.org/10.1002/anie.200460587

24. Shaabani, A. Appl. Catal. A: Gen. 2007, 331, 149-151. http://dx.doi.org/10.1016/j.apcata.2007.07.021

25. Murthy, Y.; Rajack, A.; Taraka Ramji, M.; Praveen, C.; Aruna Lakshmi, K. Bioorg. Med. Chem. Lett. 2012, 22, 6016-6023. http://dx.doi.org/10.1016/j.bmcl.2012.05.003

26. Alinezhad, H.; Haghighi, A. H.; Salehian, F. A. Chin. Chem. Lett. 2010, 21, 183-186. http://dx.doi.org/10.1016/j.cclet.2009.09.001

27. Nemati, F.; Elhampour, A. Sci. Iran. 2012, 19, 1594-1596. http://dx.doi.org/10.1016/j.scient.2012.10.015

28. Patai, S., Ed., The Chemistry of Diazonium and Diazo Groups, Wiley: New York, 1978, Chapter 14.

29. Maddila, S.; Momin, M.; Lavanya, P.; Rao, C. V. J. Saudi Chem. Soc. 2012. http://dx.doi.org/10.1016/j.jscs.2012.06.008

30. Venu, M. J.; Thirupathi, R. Y.; Narsimha, R. P.; Nikhil, R. M.; Kuarm, S.; Crooks, P. A.; Rajitha, B. J. Mol. Catal. A: Chem. 2009, 304, 85-87.

http://dx.doi.org/10.1016/j.molcata.2009.01.028

31. Sarma, R. J.; Baruah, J. B. Dyes Pigments 2005, 64, 91-92. http://dx.doi.org/10.1016/j.dyepig.2004.03.010

32. Khosropour, A.R.; Khodaei, M.M.; Moghannian, H. Synlett 2005, 6, 0955-0958. http://dx.doi.org/10.1055/s-2005-864837

33. Safari, J.; Banitaba, S. H.; Khalili, S. D. J. Mol. Catal. A: Chem. 2011, 335, 46-50. http://dx.doi.org/10.1016/j.molcata.2010.11.012

34. Mofakham, H.; Hezarkhani, Z.; Shaabani, A. J. Mol. Catal. A: Chem. 2012, 360, 26-34. http://dx.doi.org/10.1016/j.molcata.2012.04.002

35. Rajack, A.; Yuvaraju, K.; Praveen, C.; Murthy, Y. J. Mol. Catal. A: Chem. 2013, 370, 197204.

http://dx.doi.org/10.1016/j.molcata.2013.01.003

36. Rahmatpour, A. React. Funct. Polym. 2011, 71, 80-83. http://dx.doi.org/10.1016/j.reactfunctpolym.2010.11.001

37. Shaw D. J.; Wood W. F. J. Chem. Educ. 1992, 69, A313. http://dx.doi.org/10.1021/ed069pA313.1 
38. Drewes, S. E.; Hogan, C. J. Synth. Commun. 1989, 19, 2101-2107. http://dx.doi.org/10.1080/00397918908052604

39. Raghavan, S.; Anuradha, K. Synlett 2003, 711-713. http://dx.doi.org/10.1055/s-2003-38369

40. Shaabani, A.; Rahmati, A.; Badri, Z. Catal. Commun. 2008, 9, 13-16. http://dx.doi.org/10.1016/j.catcom.2007.05.021

41. Arcadi, A.; Chiarini, M.; Giuseppe, S. D.; Marinelli, F. Synlett 2003, 0203-0206.

42. Shaabani, A.; Rezayan, A. H.; Behnam, M.; Heidary, M. C. R. Chim. 2009, 12, 1249-1252. http://dx.doi.org/10.1016/j.crci.2009.01.006 44

43. Liu, B.; Zhang, Z.; Huang, K. Cellul. 2013, 20, 2081-2089. http://dx.doi.org/10.1007/s10570-013-9944-0

44. Shaabani, A.; Maleki, A.; Moghimi Rad, J.; Soleimani, E. Chem. Pharm. Bull. 2007, 55, 957958. http://dx.doi.org/10.1248/cpb.55.957

45. Shaterian, H. R.; Rigi, F.; Arman, M. Chem. Sci. Trans. 2012, 1, 155-161. http://dx.doi.org/10.7598/cst2012.137

46. Nemati, F.; Elhampour, A. J. Chem. Sci. 2012, 124, 889-892. http://dx.doi.org/10.1007/s12039-012-0261-1

47. Kuarm, B. S.; Madhav, J. V.; Laxmi, S. V.; Rajitha, B.; Reddy, Y. T.; Reddy, P. N.; Crooks, P. A. Synth. Commun. 2011, 41, 1719-1724. http://dx.doi.org/10.1080/00397911.2010.492076

48. Kuarm, B. S.; Crooks, P. A.; Rajitha, B. Green Chem. Lett. Rev. 2013, 6, 228-232. http://dx.doi.org/10.1080/17518253.2012.752041

49. Reddy, P. N.; Reddy, Y. T.; Reddy, M. N.; Rajitha, B.; Crooks, P. A. Synth. Commun. 2009, 39, 1257-1263. http://dx.doi.org/10.1080/00397910802517871

50. Oskooie, H. A.; Heravi, M. M.; Tahershamsi, L.; Sadjadi, S.; Tajbakhsh, M. Synth. Commun. 2010, 40, 1772-1777. http://dx.doi.org/10.1080/00397910903161777

51. Kuarm, B. S.; Madhav, J. V.; Rajitha, B.; Reddy, Y. T.; Reddy, P. N.; Crooks, P. A. Synth. Commun. 2011, 41, 662-669. http://dx.doi.org/10.1080/00397911003632899

52. Sadaphal, S.; Sonar, S.; Ware, M.; Shingare, M. Green Chem. Lett. Rev. 2008, 1, 191-196. http://dx.doi.org/10.1080/17518250802637819

53. Shelke, K. F.; Sapkal, S. B.; Kakade, G. K.; Shingate, B. B.; Shingare, M. S. Green Chem. Lett. Rev. 2010, 3, 27-32. http://dx.doi.org/10.1080/17518250903505246

54. Mosaddegh, E.; Hassankhani, A.; Baghizadeh, A. J. Chil. Chem. Soc. 2010, 55, 419-420. http://dx.doi.org/10.4067/S0717-97072010000400001 
55. Rezaei, R.; Sheikhi, M. R. Res. Chem. Intermed. 2013, 1-10. DOI 10.1007/s11164-013-12723. http://dx.doi.org/10.1007/s11164-013-1272-3

56. Jin, T.; Zhang, S.; Li, T. Synth. Commun. 2002, 32, 1847-1851. http://dx.doi.org/10.1081/SCC-120004068

57. Bigi, F.; Carloni, S.; Frullanti, B.; Maggi, R.; Sartori, G. Tetrahedron Lett. 1999, 40, 34653468.

http://dx.doi.org/10.1016/S0040-4039(99)00424-4

58. Hu, E. H.; Sidler, D. R.; Dolling, U. H. J. Org. Chem. 1998, 63, 3453-3457.

59. Rezaei, R.; Malek, S.; Sheikhi, M. R.; Mohammadi, M. K. Chem. J. Moldova 2013, 8, 101106.

60. Hatamjafari, F. Helv. Chim. Acta. 2013, 96, 1560-1563.

http://dx.doi.org/10.1002/hlca.201200621

\section{Authors' Biographies}

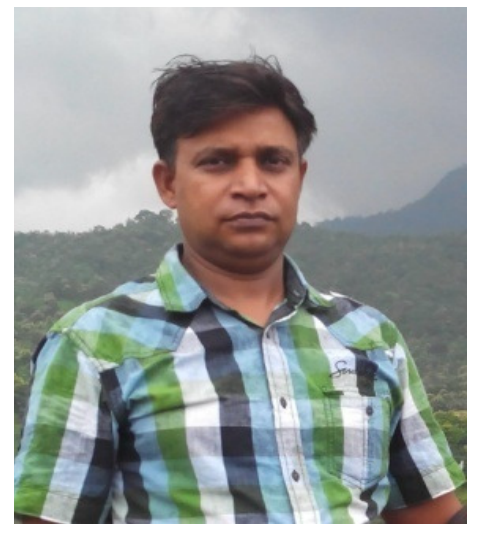

Dr. Hitesh D Patel has received his Ph.D in Organic Chemistry from the South Gujarat University, Surat, Gujarat, India in 2005 under the supervision of Dr. B. D. Mistry of B. K. M. Science College, Valsad, Gujarat, India. He worked on the synthesis of biologically active heterocyclic compounds, their characterization by various analytical techniques and their testing for activities. He joined as a lecturer at St. Xavier's College, Ahmedabad, Gujarat, India and also had been associated with Xavier Research Foundation, Ahmedabad, India, during the period of 1998 to 2005. Since then he has joined as an Associate Professor at Department of Chemistry, Gujarat University, Ahmedabad, Gujarat, India. At present the field of the research area is synthetic organic chemistry via green chemistry, biological screening of synthesized compounds, the computational study of active organic molecules, study of organic fluorescence giving compounds on infectious microorganisms and also scales up of industrially important compounds. 


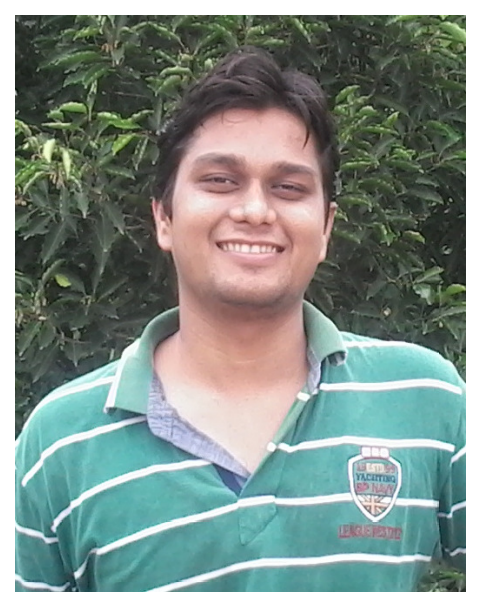

Rajesh H. Vekariya obtained his B.Sc. Degree in Chemistry in 2010 and his M.Sc. Degree in organic chemistry in 2012 both from the Gujarat University, Ahmedabad (India). Currently, he is pursuing his Ph.D. under the guidance of Dr. Hitesh D. Patel at the Chemistry Department of the Gujarat University, Ahmedabad. His research focuses on the synthesis of organic intermediates via green chemistry and their utilization in the synthesis of biologically active compounds. His research focuses on synthesis of industrially important organic intermediates by step down process and development of more eco-friendly and economical methods. He is working on highly important and basic industrial processes such as nitration, bromination, oxidation and reduction. 